\title{
Atualizando o Debate entre Piaget e Chomsky em uma Perspectiva Neurobiológica ${ }^{1}$
}

\author{
Marcelo Leandro Eichler ${ }^{2}$ \\ Lea Fagundes \\ Universidade Federal do Rio Grande do Sul
}

\begin{abstract}
Resumo
Os entendimentos sobre a aquisição da linguagem e sobre as estruturas cognitivas estão em debate no seio das ciências cognitivas. Isso se dá apesar de um grupo de acadêmicos, de forma retórica, insistir em desmerecer o modelo construtivista piagetiano, mantendo uma adesão ao inatista ponto de vista chomskyano. Nesse artigo, retoma-se o clássico debate entre esses dois sistemas de conhecimento, repensando-o em uma perspectiva psicobiológica e apresentando recentes estudos neurobiológicos que sugerem a correção do compromisso, apontado por Piaget, entre $\mathrm{o}$ inato e $\mathrm{o}$ adquirido.

Palavras-chave: Construtivismo; inatismo; epistemologia genética; neurobiologia.
\end{abstract}

Updating the Debate between Piaget and Chomsky in a Neurobiological Perspective

\begin{abstract}
The understandings of language acquisition and of cognitive structures are in debate in the center of the cognitive sciences. It happens despite of a group of academics who, in a rhetorical way, insists on despising Piaget's constructivist model, keeping a connection to Chomsky's innatist theory. This paper recalls the classical debate between these two knowledge systems, rethinking it in a psychobiological perspective and presenting recent neurobiological studies that suggest a correction of commitment between innate and acquired as pointed by Piaget.

Keywords: Construtivism; innatism; genetic epistemology; neurobiology.
\end{abstract}

Eu não tenho, de forma alguma, a ambição de decidir entre um tudo e um nada, mas apenas a candura de querer diferenciar as situações e de julgar que ganhei em todos os planos. (Piaget, 1987, p. 399)

O debate em torno de teses parece ser uma das características da ciência. Uma visão tradicional em filosofia das ciências (Hegenberg, 1969) indica que o desenrolar do debate envolveria, de parte a parte, a exposição de dados (de informação, empíricos ou experimentais) e da tese que deles se retira por conclusão. A marcha dessa exposição levaria à necessidade de explicar ou justificar tais conclusões e, em muitos casos, envolveria uma argumentação ampla e matizada. O desenvolvimento da argumentação poderia conter: a) garantias teóricas, que são os enunciados hipotéticos a que se faz apelo para justificar a passagem dos dados à conclusão; b) qualificadores, que restringem as conclusões e estabelecem as condições e os termos em que ela se torna mais aceitável; e, c) suportes para as garantais, que se destina a conferir autoridade às garantias, trazendo mais dados ou informações teóricas.

Nesse esquema, como se pode observar pela coesão racional, parece não haver espaço para a retórica. Conforme Abbagnano (1999), a retórica é a arte de persuadir com o uso de instrumentos lingüísticos. Essa arte tem como característica principal sua independência em relação à disponibilidade de provas ou de argumentos que produzam conhecimento real ou convicção racional. $\mathrm{O}$ objetivo da retórica é persuadir, por meio de

\footnotetext{
${ }^{1}$ Gostaria de agradecer: à CAPES pelas bolsas de doutorado e de estágio no exterior (Programa PDEE); e à Tânia Sperb e Silvia Parrat-Dayan pelas leituras atentas às versões anteriores desse manuscrito.

${ }^{2}$ Endereço para correspondência: Av. Bento Gonçalves, 9500, Sala D114, Campus do Vale, 91501 970, Porto Alegre, RS.E-mail:exlerbr@yahoo.com.br
}

discursos, aqueles que devem tomar partido de uma ou outra tese em algum tribunal, conselho, assembléia ou outra reunião pública. Portanto, o retórico é hábil em convencer a maioria das pessoas sobre qualquer assunto, falando contra todos que se lhe oponham e conseguindo ser mais persuasivo que qualquer debatedor.

Por isso, alguém poderia mesmo supor que a retórica estaria mais pertinente à política ou ao Direito. Isso não seria inimaginável, uma vez que pelo ideal da objetividade científica, o sujeito poderia afastar seu tom discursivo das características pejorativas da oratória, que aproximam a retórica ao discurso pomposo e empolado, porém vazio de conteúdo. Entretanto, aí se estaria esvaziando o conteúdo da própria retórica.

No entanto, mesmo na ciência moderna o uso da retórica como ferramenta de persuasão se encontra disseminado. Regner (1998) desenvolveu um exame dos procedimentos explicativos e das estratégias argumentativas encontradas no clássico Origem das Espécies, de Charles Darwin. Entre as estratégias argumentativas que poderiam ser entendidas como retóricas Regner lista as seguintes: a) defender a teoria, 'deslocando' o teor da objeção; b) alegar que a evidência desfavorável não existe; c) alegar que a evidência disponível não é fatal à teoria; d) alegar que a evidência arrolada foi adequadamente examinada; e) alegar que a evidência não desqualifica a teoria; $\mathrm{f}$ ) alegar que as evidências favoráveis e desfavoráveis devem ser assim examinadas à luz da integridade do contexto explicativo; g) alegar que a evidência não afeta qualquer teoria em particular, ou que, em qualquer caso, não dispõe de sólido fundamento; h) alegar que a evidência arrolada não afeta ao adversário; i) alegar ter sido malinterpretado; j) desqualificar as razões da teoria do oponente; 1) desqualificar a evidência favorável e enfatizar a evidência 
favorável à teoria; m) examinar detidamente os aspectos aparentemente favoráveis da teoria que coloca a dificuldade ou a objeção e logo apontar sua deficiência; e, n) apelo à nossa ignorância (quando não se dispõe de razões a dar).

Nos livros de divulgação científica ou nos manuais didáticos da ciência cognitiva, p. ex., a maioria dessas estratégias argumentativas pode ser encontrada. Como não se quer ser demasiado retórico em relação ao cognitivismo tradicional, nas próximas seções situa-se o debate entre as perspectivas de Chomsky e de Piaget, procurando-se repensá-lo em uma perspectiva psicobiológica, indica-se alguns argumentos retóricos que são utilizados para deter o debate e, finalmente, apresenta-se uma revisão de artigos em neurobiologia que corroboram o compromisso entre o inato e o adquirido suposto por Piaget (1996).

\section{Situando o debate}

Em outubro de 1975 foi promovido pelo Centro Royaumont para uma Ciência do Homem um simpósio cujo objetivo era propiciar um debate entre os programas científicos de Chomsky (a lingüística generativa) e de Piaget (a epistemologia genética), considerados, à época, em pleno desenvolvimento e paradigmáticos. Esse debate contou com a participação de pesquisadores de diversas áreas como: lingüística, psicologia, epistemologia, neurobiologia, etologia, psicologia animal, antropologia, inteligência artificial e filosofia. Pensava-se, através desse debate, procurar possíveis relações entre o inato e o adquirido, entre estruturas biológicas e estruturas cognitivas.

Conforme o organizador do livro que resultou desse simpósio, Piattelli-Palmarini (1978/1987), ao realizar uma confrontação direta e aprofundada entre tais programas científicos, supunha-se chegar a uma síntese transdisciplinar dos temas em debate. Um objetivo, obviamente, muito audacioso. Uma demonstração menos ambiciosa desse debate pode ser encontrada, p. ex., nas entrevistas empreendidas, por Rieber e Voyat (1981), com alguns de seus participantes.

Nos próximos parágrafos, revisa-se esse debate, procurando mostrar alguns depoimentos dos debatedores. Obviamente, essa é uma reconstrução entre outras possíveis.

Uma vez que a defesa do programa científico de Chomsky é feita, alguns anos mais tarde, pelo organizador do livro originado nesse debate (Piattelli-Palmarini, 1994), começa-se por se situar o debate através das posições iniciais assumidas por Chomsky (1978/1987).

Para esse lingüista, a linguagem humana seria vista como uma capacidade geneticamente determinada, como uma componente do espírito humano, que especificaria uma certa espécie de gramáticas humanamente acessíveis. A gramática é, por ele, entendida como um sistema que especifica as propriedades fonéticas, sintáticas e semânticas de uma série infinita de frases possíveis. Por isso, no seio de uma determinada comunidade lingüística, mesmo entre crianças com experiências pessoais singulares são adquiridas gramáticas comparáveis. Dessa forma, assim como para as gramáticas, Chomsky supõe que exista um sistema fixo e geneticamente determinado que balize o desenvolvimento de toda linguagem.

Resumindo sua posição inicial no debate, pode-se dizer que Chomsky presume que a criança desenvolve estruturas cognitivas de forma análoga, balizadas pelo herdado. Nesse sentido, ele compara os órgãos físicos com o que chama de órgãos mentais. Tanto uns como outros seriam determinados por propriedades próprias à espécie e geneticamente determinados. Apesar de, nos dois casos, a interação com o ambiente ser necessária para desencadear o desenvolvimento, porque influi sobre as estruturas que se desenvolvem e as modela, Chomsky declara que a interação do organismo com o ambiente é insuficiente para dar conta do caráter e da origem das estruturas mentais de base (Ex.: a estrutura sintática das linguagens). Ou seja, há alguma coisa de inato na origem dessas estruturas mentais.

Por outro lado, conforme Piaget (1978/1987), também ao início do debate, não existiriam no homem estruturas cognitivas a priori ou inatas. Somente o funcionamento da inteligência seria hereditário, engendrando as estruturas a partir da organização de ações sucessivas exercidas sobre os objetos físicos e, depois, mentais. Por isso, ele compreende que o problema epistemológico central do debate é entender como se efetuam as criações cognitivas e porque, resultando de construções não prédeterminadas, elas podem se tornar logicamente necessárias durante a ontogênese.

Nesse sentido, Piaget assevera que, assim como nos processos biológicos, a auto-regulação também é comum aos processos mentais, cujas raízes são evidentemente orgânicas. A autoregulação é, ao mesmo tempo, capaz de conservar o passado e de se ultrapassar sem cessar. Ao se ultrapassar, a auto-regulação se torna uma auto-organização, que conduz a estruturas novas. Portanto, Piaget sugere que é na direção da auto-organização, e não apenas na hereditariedade, que convém procurar a explicação biológica das construções cognitivas e da aquisição da linguagem.

Nesse momento, cabe lembrar que neste artigo não serão abordados todos os temas que foram debatidos naquela ocasião, até porque isso exige um trabalho de maior envergadura, envolvendo diversas áreas de conhecimento. Além do mais e pelo mesmo motivo, também, não serão discutidos todos os temas relacionados à biologia. Com isso, quer-se dizer que não serão questionados os dados que justificam as conclusões de Piaget e Chomsky sobre a linguagem e a aprendizagem. A atenção será restrita ao sistema neural que serve de substrato à emergência das faculdades mentais.

Então, antes que se apresentem algumas idéias que cruzaram o debate, vale refinar os termos do desacordo, que não é tanto entre o inato e o adquirido, como se colocou ao início. O embate entre as opiniões parece se dar entre compreensões biológicas: 
serão a linguagem e a cognição geneticamente determinadas (Chomsky) ou auto-organizáveis na interação entre o agente e o ambiente (Piaget)?

Durante o debate em si, Chomsky criticou o fato das estruturas cognitivas desenvolvidas pelo espírito serem geralmente consideradas e estudadas de forma diferente das estruturas orgânicas desenvolvidas pelo corpo. Por isso, sugere que: não há raz̃ão alguma para que um pesquisador independente, livre de qualquer doutrina tradicional, adote esta maneira de ver (p. 65). Então, aconselha que o pesquisador aborde o estudo de estruturas cognitivas, como a linguagem humana, de uma maneira análoga àquela segundo a qual estudaria um órgão como o olho, o fígado ou o coração, procurando determinar: 1) as suas características num indivíduo dado; 2) as suas propriedades gerais, invariáveis de uma espécie para outra, fazendo abstração de qualquer ausência flagrante; 3) o seu lugar num sistema de estrutura desse tipo; 4) o curso do seu desenvolvimento no indivíduo em questão; 5) o fundamento geneticamente determinado deste desenvolvimento; e, 6) os fatores que fizeram nascer esse órgão mental no decurso da evolução. Dessa forma, Chomsky supõe que se confirmaria o determinismo genético na emergência da gramática universal e de outras estruturas cognitivas.

Essa proposta parece necessitar de uma aclaração sobre as efetivas relações entre o indivíduo (pontos 1 e 4) e a espécie do qual faz parte (pontos 2, 3, 5 e 6). Em outros termos, pode-se dizer que é necessário procurar pelas relações entre a ontogênese e a filogênese, e isso em relação à cognição e à linguagem.

O programa científico de Piaget (1970, 1977, 1967/1996) não se eximiu de tais necessidades. Porém, Chomsky nega a plausibilidade da hipótese piagetiana de que as construções da inteligência sensório-motora possibilitam o caráter da função mental. Essa negação tem como âncora a sua analogia dos órgãos mentais, pois tal hipótese lhe parece tão difícil como aceitar afirmações segundo as quais as propriedades fundamentais do olho, ou do córtex visual, ou do coração se desenvolvem a partir das ações sensório-motoras.

Como sempre, é preciso um certo cuidado com a interpretação de teses, pois conforme indicou Papert (1978/1987) durante o debate, é uma interpretação ingênua dizer que para Piaget nada é inato e tudo emerge do desenvolvimento. Não é próprio da obra de Piaget esse tipo de dualismo, pelo contrário suas interpretações costumam ser dialéticas.

Então, o que afirma Piaget, em um típico corte para efeito de estudo, é que: se se estabelecer uma lista das estruturas, das nocõoes e das regras (qualquer que seja o nome que se lhes dê) presentes na inteligência do adulto, e se se perguntar qual destas é inata, a resposta será 'nenbuma' (p. 147). Dessa forma, em relação à cognição, o que for pensado como inato não será uma parte separável do espírito adulto.

Portanto, uma vez que Piaget recusa a hipótese de uma préprogramação em sentido restrito, o que ele considera inato é uma capacidade geral de recompor os sucessivos níveis de uma organização cognitiva cada vez mais avançada (Inhelder, 1978/ 1987). Além do mais, é preciso admitir que tais capacidades inatas, para as quais existem provas neurológicas, estão montadas no sistema nervoso central (Toulmin, 1978/1987, p. 391).

Isso é útil para pôr em evidência a história do desenvolvimento do sistema cognitivo (S). P. ex., ao nascimento do bebê, tem-se o estado inicial do sistema $\left(\mathrm{S}_{0}\right)$. Em algum momento, ele atinge o estado final $\left(\mathrm{S}_{\mathrm{f}}\right)$. No intervalo entre tais estados, existem vários estados intermediários $\left(\mathrm{S}_{\mathrm{i}}\right)$, alguns singulares, que são úteis para contar a história desse desenvolvimento. Com isso, é possível interpretar que grande parte da obra de Piaget esteve relacionada à pesquisa das entidades intermediárias suscetíveis de desempenhar um papel de precursor das estruturas cognitivas presentes no adulto ou até na criança, seja qual for a sua idade. Porém, conforme Papert (1978/1987), $\mathrm{S}_{0}$ e $\mathrm{S}_{\mathrm{f}}$ são estruturas profundas e não são diretamente acessíveis. Por conseqüência, surgem divergências entre diferentes observadores desse sistema e isso se manifesta através de suas proposições teóricas, como no caso do debate que está sendo revisado.

Nessa compreensão, segundo Toulmin (1978/1987), as capacidades particulares que Chomsky atribui à criança, como a da gramática universal (que constrange o universo de busca gramatical e a seleção de palavras e de estruturas sintáticas), são aparentemente muito específicas para serem verossímeis e parece difícil conceber quais poderiam ser as suas contrapartidas neurológicas. Assim, não seria propriamente uma regra lingüística que seria inata, mas um precursor mais geral o que, em si, conduz a tese de Chomsky para uma posição mais piagetiana (Papert, 1978/1987, p. 152).

Além disso, Piaget indica que sua hipótese de precursores da linguagem produzidos pela inteligência sensório-motora foi admitida, de forma independente, por pesquisadores da origem da linguagem, como Roger Brown e Eric Lenneberg. Ainda que seja isso retórico poderia ser uma mostra suficientemente que a bipótese do inatismo é inútil para a coerência do belo sistema de Chomsky (Piaget, 1978/1987, p. 59).

Entretanto, em uma perspectiva neurobiológica, é possível verificar que, embora a metáfora cérebro-fígado possa até ser útil para um público de lingüistas, ela é enganadora para psicólogos e biólogos, como declarou Changeux (1978/1987) durante o debate. Isso justamente porque o neurônio é infinitamente mais complexo que um hepatócito. A maior complexidade está relacionada aos prolongamentos axôniais e dendríticos que possuem o neurônio. Dessa forma, o neurônio pode estar em relação com vários milhares de outras células, em diversos conjuntos, o que certamente um hepatócito não pode fazer. Assim, as funcöes essenciais do sistema nervoso, e em particular a capacidade de aprender, são determinadas por estas relaciōes intercelulares (p. 268).

Normalmente, o próprio sistema nervoso humano é considerado tanto pelo lingüista, quanto pelo psicólogo como uma caixa negra. Somente as regras das relações entrada-saída 
são descritas no adulto normal ou no decurso do desenvolvimento. Uma descrição satisfatória de qualquer comportamento, que superasse esse modelo de caixa negra, deveria obrigatoriamente incluir: 1) a anatomia dos circuitos neurônicos referidos; 2 ) a atividade desses circuitos; e, 3) os sinais que o organismo recebe através dos órgãos sensoriais. Tal tarefa parece ampla por demais na prática, mas é possível em teoria. Essa proposição, sem dúvida, é mais fácil de ser realizada em sistemas simples. P. ex., o determinismo genético é quase absoluto num pequeno invertebrado, um nematóide ou um crustáceo. Mas é bem menos rigoroso no cérebro de um vertebrado. Por isso, a dificuldade que se tem em sistemas mais complexos, como os associados à cognição, em geral, e à linguagem, em particular.

Conforme Changeux (1978/1987), a fraca quantidade de informação genética disponível contrasta com a extrema complexidade estrutural do sistema nervoso central. Por ocasião do debate, ainda, declarou que: nada se obteve das tentativas para encontrar relacoues fundamentais entre codificação genética e armaženagem da informação no cérebro (p. 268). Entretanto, Changeux indicou que já no começo do Século XX, o mecanismo proposto por Ramón y $\mathrm{Cajal}^{3}$ reteve a atenção de gerações de neurobiólogos: o estado de atividade do sistema nervoso em desenvolvimento participa no estabelecimento da conectividade final (p. 274). Nesse sentido, pode-se postular que o programa genético dirige a interasãa conveniente entre as principais categorias de neurônios (p. 276). Porém, como será mostrado em uma próxima seção, o funcionamento desse mecanismo ainda está em debate.

Após a entrada da perspectiva neurobiológica no debate, Piaget agradece a Changeux por ter analisado os compromissos possíveis entre ele e Chomsky. Também declara que, durante o simpósio, pretendeu encontrar esse compromisso, ao admitir a hereditariedade de funcionamento das próprias construções. Finalmente, ressalvou: não conbeço nada de neurologia, mas ao ler um trabalho de Paul Weisst sobre a formação do sistema nervoso, fui tocado pela sua recusa em admitir uma programação fixa e sua insistência em querer mostrar variações, possiveis também, segundo os indivíduos (p. 281).

$\mathrm{Na}$ introdução do livro que resultou do simpósio, apesar das manifestações divergentes arroladas até aqui, o seu organizador (Piattelli-Palmarini, 1978/1987) professara um ato de fé em um exercício de futurologia:

[na verdade] a elaboração mental dos dados lingüísticos traduzir-seia por uma classe de sucessões particulares entre estes micro-estados [neurônicos, caracterizados por separações discretas entre parâmetros locais] ... é preciso pensar que os neurobiólogos do ano 2000 se

\footnotetext{
${ }^{3}$ Santiago Ramón y Cajal $(1852$ - 1934) foi agraciado com o Prêmio Nobel de Fisiologia e Medicina, juntamente com Camillo Golgi (1843-1926), em 1916, por seus estudos sobre a estrutura do córtex cerebral.

${ }^{4}$ Paul A. Weiss (1898-1989) foi durante mais de quatro décadas pesquisador no Rockfeller Center e conduziu importantes pesquisas sobre o sistema nervoso de vertebrados que contribuíram para o desenvolvimento da neurobiologia.
}

encarregarão de precisar a natureza destes estados. ... Se semelhante realização pertence ainda ao domínio da ficção científica, o que importa, doravante, é que esta identidade não parece colocar qualquer problema de princípio. (p. 43)

Essa tendência de desautorizar, silenciar e/ou eliminar a perspectiva que é divergente em relação a que adota, usando com habilidade o arsenal retórico, é bastante utilizada por PiattelliPalmarini e pode ser evidenciada nas introduções e nas conclusões que faz a cada capítulo do livro.

Quase duas décadas depois do simpósio, Piattelli-Palmarini (1994) volta ao assunto do debate em um artigo de revisão. Nele presume que os recentes desenvolvimentos em gramática generativa e os novos dados em aquisição da linguagem, associados a refinamentos teóricos da tese de Chomsky, refutam a hipótese piagetiana que a linguagem é construída sobre abstrações de esquemas sensório-motores.

Este artigo não trata da gramática generativa e da aquisição da linguagem natural, portanto não serão apresentados dados que refutem ou corroborem as teses de Chomsky ou de Piaget. Dessa forma, o parágrafo anterior serve para evidenciar a adesão de Piattelli-Palmarini.

Conforme Piattelli-Palmarini (1994), Piaget assumira que concordaria com Chomsky em todos os tópicos importantes, chegando a afirmar que poderia haver um compromisso entre suas posições. Segundo sua compreensão, Piaget considerava que o potencial divisor do debate sobre o inatismo seria, ao final, um não-debate (ou pelo menos não um divisor) porque ele também concordava que existe um núcleo fixo subjacente a todas as atividades mentais, inclusive a linguagem, e que este núcleo é considerado pela biologia humana. O único debate, então, seria avaliar a exata natureza deste núcleo fixo e o grau de sua especificidade. Nesse novo debate, a posição piagetiana consistiria na minimização do papel de fatores inatos, enquanto a chomskyana indicaria a maximização desses fatores.

No mesmo artigo, mais adiante, Piattelli-Palmarini (1994) conjectura que a visão de Piaget sobre a natureza, a origem e a evolução do núcleo fixo sofrera severa crítica dos biólogos moleculares presentes ao debate, citando François Jacob e Jéan-Pierre Changeux, principalmente em relação à sua noção de fenocópia. Nesse caminho, o autor chega a falar da alienação de Piaget da tendência atual da biologia e que ela foi consumada outra vez durante o simpósio, assim: evidentemente, ele não sabia sobre o que estava falando (p. 325).

Pode-se facilmente refutar esses argumentos retóricos. Podem ser dados três contra-argumentos, depreendidos do próprio livro que resultou do debate (Piattelli-Palmarini, 1978/ 1987). Primeiro, não há a declarada alienação de Piaget sobre a biologia atual, mesmo porque Piaget concordou com as compreensões de Changeux sobre a fenocópia. Segundo, isso descaracteriza Piaget como biólogo de formação. Terceiro, 
não demonstra que a convergência do pensamento entre os biólogos Piaget e Changeux se dá basicamente sobre os mesmos autores: Ludwig von Bertallanfy e Ernst Mayr, p. ex.

Seguindo o curso da argumentação, Piattelli-Palmarini (1994) supõe que a falta de percepção de Piaget em compreender as diferenças fundamentais entre as suas posições e as de Chomsky foi, em essência, responsável pela lacuna entre o debate surgido no simpósio e o debate posterior, que Piaget esperava ser hábil para idealizar. Para esse autor, com o passar dos anos, tornou-se evidente que o debate não foi o que Piaget esperava, além do mais comegon a ficar claro para qualquer um, exceto possivelmente para o próprio Piaget, que nenbum compromisso poderia possivelmente ser achado (p. 321).

Esse é outro argumento teórico que pode ser contestado. Pode-se verificar, p. ex., a partir de uma interpretação da filosofia das ciências (Bunge, 1988; Bunge \& Ardila, 1987) que a falta de compreensão estaria com Chomsky, a quem faltara, entre outras coisas, uma aclaração semântica sobre o termo 'inato'. Bunge e Ardila (1987) alertam para não se fazer confusão entre os termos herdado e inato. Veja-se: o repertório de comportamento inato de um animal é parte do repertório de comportamento herdado. P. ex., todos os mamíferos podem mamar desde o primeiro momento, esse é um comportamento inato. Mas alguns não andam até vários meses depois, tal comportamento é herdado. Embora esteja também programado, não está maduro no momento do nascimento. Somente o organismo adulto possui completo o repertório da conduta herdada. Em resumo, se dá a inclusão: Inato $C$ Herdado C Total. Segundo Bunge, Chomsky não se ocupou de distinguir entre inato e de nascimento (herdado) quando afirmou que a gramática universal é um esquema inato. Bunge entendeu que a capacidade de aprender coisas tais como uma gramática universal é uma capacidade que possuímos de nascimento, mas que o processo real de aprendizagem não se dá até depois do estágio do balbucio.

A revisão empreendida por Piattelli-Palmarini (1994) compreendeu somente os trabalhos sobre o desenvolvimento em lingüística e aquisição da linguagem com viés em Chomsky. Em seu artigo, chega inclusive, em nota de rodapé, a agradecer a Noam Chomsky pelas sugestões e revisões que fizera no texto original. Ele nada cita sobre a outra posição do debate, que foi representada, no simpósio, por Jean Piaget, Bärbel Inhelder e Simon Papert, p. ex.

Por fim, Piattelli-Palmarini também apóia suas asserções sobre as compreensões neurobiológicas inatistas do programa científico de Changeux.

Entretanto, este artigo não é um artigo de réplica às posições de Piattelli-Palmarini (1994). Elas são citadas para mostrar os equívocos ou os objetivos que o uso da retórica pode ensejar: encerrar um debate que segue em curso na arena científica.
Então, seguindo uma perspectiva piagetiana - que procura uma síntese de perspectivas através da integração de dados de pesquisa e de teorias de diversos ramos do conhecimento, e quando isso não é possível procura preservar o debate serão apresentadas nas próximas seções refutações à conclusão de Piattelli-Palmarini (1994) que o debate estaria encerrado, que ele seria tanto impossivel como indesejável (p. 342) e que o prêmio iria para Noam Chomsky.

\section{Repensando o debate}

Conforme Bunge e Ardila (1987), a psicologia poderá adquirir no Século XXI o glamour que distinguiu a física na primeira metade do Século XX e que a biologia possuiu na segunda (e ainda hoje). Entretanto, para esses autores, a chegada nesse patamar envolveria tanto uma reorientação filosófica da comunidade de psicólogos, quanto à observância de dados experimentais disponibilizados pelo conjunto mais amplo do pensamento científico. A direção dessa perspectiva poderia assumir muitos nomes, um deles seria a psicobiologia.

Para esses autores, seria preciso assumir que uma psicologia do desenvolvimento (ou genética) pura (sem cérebro) nada explicaria. Portanto o desenvolvimento humano seria compreendido como um processo biossocial de reorganização neural entrelaçado com socialização. Assim, somente uma biopsicologia desenvolvimentista unida com uma psicologia social incluiria a promessa de explicações científicas que visem ao desenvolvimento. Entretanto, nesse artigo o foco está somente sobre o biossistema neural.

$\mathrm{Na}$ perspectiva psicobiológica, assume-se que o comportamento é um resultado de processos neurônicos, que são algumas vezes provocados por estímulos externos. Nesse sentido, considera-se que os estados mentais são estados cerebrais de um tipo especial. Dessa forma, os processos comportamentais e mentais, para efeitos de estudo, podem ser agrupados em três grandes famílias: motor, afetivo e cognitivo. As atividades motoras seriam as funções específicas do sistema neuromuscular. Os processos afetivos (prazer, dor, amor, ódio, raiva, ansiedade, etc.) estariam relacionados ao sistema límbico. Finalmente, os processos cognitivos (percepção, imaginação, pensamento, etc.) seriam as funções específicas dos sistemas córtico-talâmico e córtico-límbico.

Nessa direção, Bunge (1988) reconhece a importância de Piaget e de Chomsky para o debate sobre mente e cérebro. Conforme esse autor, Piaget começou a investigar a emergência e o desenvolvimento das capacidades mentais nas crianças e nos adolescentes. Por sua vez, Chomsky lançou um ataque direto contra a psicologia sem mente - entretanto, lamentavelmente, sem preservar o sistema nervoso.

Bunge (1988) sugere que os debates em torno da mente devem ser tomados em uma orientação filosófica que ele denomina por materialismo emergentista (ou sistêmico). O 
emergentismo se expressa por uma tese segundo a qual a mentalidade é uma propriedade emergente que somente possuem os animais dotados de um sistema nervoso extremamente complexo e plástico. Assim, nessa perspectiva, compreende-se que:

... o SNC [sistema nervoso central] não é uma entidade física nem, em particular, uma máquina - senão que é um biossistema, isto é, uma coisa complexa dotada com propriedades e leis peculiares dos seres vivos, algumas muito peculiares - ou seja: algumas das leis e propriedades que possui o SNC não as compartilham todos os biossistemas. (p. 28)

Como todo biossistema, o SNC não é invariável, ele tem tanto uma história em relação à vida do animal (ontogênese), quanto ao longo da história das populações animais (filogênese). Presume-se que deva existir, ainda, algum grau de integração entre essas histórias.

É necessário ressaltar que o materialismo emergentista não resolveu por si só o problema mente-cérebro. Não o fez e não o fará porque o materialismo emergentista é uma filosofia que somente proporciona um andaime para a investigação científica detalhada dos principais problemas sobre o humano. Segundo Bunge (1988), essa empreitada científica pertence, principalmente, aos neurocientistas, aos psicólogos e aos neurologistas. E eles devem atacar [esse problema] como cientistas, não como filósofos aficionados, nem como teólogos (p. 230). É nesse sentido, que na seção anterior se quis evidenciar o uso da retórica na ciência. A seguir, restringe-se foco nos processos cognitivos.

Uma das mais vivazes e recentes controvérsias no debate sobre o inato e o adquirido está relacionada à aprendizagem da linguagem (Bunge \& Ardila, 1987). Conforme o materialismo emergentista, compreende-se que a aprendizagem envolve a aquisição de funções neurônicas novas e requer a presença de sistemas neurônicos plásticos (também chamados de psicones). Dessa forma, a plasticidade é uma disposição neurônica, a aprendizagem sua realização (Bunge, 1988).

Em nível biológico, a aprendizagem consiste no reforço das conexões sinápticas (hipótese de Donald $\mathrm{Hebb}^{5}$ ). Essas podem ser estudadas em animais relativamente simples, p. ex., os invertebrados. Tais estudos revelaram que parecem existir três tipos de sinapses, ou, melhor, de conexões sinápticas, relacionadas à aprendizagem: 1) elástica (não resulta modificação como resultado da atividade); e, 2) plástica, subdividida em duas: a) habituação (diminui quando se repete a estimulação); e, b) aprendizagem (aumenta quando se repete a estimulação).

\footnotetext{
${ }^{5}$ Donald Olding Hebb (1904 - 1985) é, muitas vezes, considerado o pai da psicobiologia cognitiva. Ele foi professor de psicologia na Universidade de McGill, no Canadá. Seu trabalho mais famoso envolveu o papel da covariação do peso sináptico entre dois neurônios.
}

Portanto, um animal que está aprendendo, está ampliando seu espaço de estados neurais. Esta ampliação pode ser: i) quantitativa, em que conserva os mesmos eixos, modulando e coordenando a atividade dos sistemas neurais previamente existentes; ou, ii) qualitativa, muda algum eixo, consistindo na emergência de novos sistemas neurais de tamanhos consideráveis.

Esses postulados, descritos por Bunge (1988), reportam aos trabalhos clássicos de Ramón e Cajal e de Hebb e encontram recentes expressões concretas e experimentais, como nos trabalhos de Diamond (2001), Quartz (1999), Quartz e Sejnowski (1997) e Rapoport (1999).

Assim, é possível dizer que toda aprendizagem, por simples que seja, é criativa, uma vez que consiste na emergência de pautas de atividade neurônica que não estão programadas geneticamente senão que foram formadas na vida do animal. Nesse sentido, Bunge (1988) conclui que: o que está programado é a capacidade de aprender (p. 157).

Além disso, a aprendizagem, também, afeta o reservatório genético e de uma maneira indireta afeta a evolução. Ou seja, por aumento ou diminuição das chances de reprodução, o comportamento aprendido pode afetar a distribuição dos genes na população (Bunge \& Ardila, 1987).

A aquisição ou a aprendizagem da linguagem possuiria uma explicação nessa direção. Compreendendo assim, o ser humano não nasce com uns conbecimentos de determinados traços estruturais básicos comuns a todas as linguagens naturais (tese de Chomsky). Nascemos com um trato vocal, com as chamadas áreas de Wernicke e de Broca e com sistemas neurônicos subsidiários. Depois, temos um meio social que estimula a aquisição e o desenvolvimento das linguagens verbais. Nosso legado anatômico e social nos permite mobilizar quantos sistemas neurônicos sejam precisos para produzir ou compreender a fala.

Obviamente, isso também teve uma evolução filogenética. O cérebro e o trato vocal devem ter evoluído harmonicamente um com o outro e ambos em relação ao meio ambiente e à sociedade. Introduções a esse tema podem ser encontradas nos livros de divulgação de Gould (1992) e de Leakey (1994).

Dessa forma, conforme sugerem Bunge e Ardila (1987), somente um estudo biopsicológico envolvendo um exame do tecido nervoso pode ser hábil para decidir se é possível (ou impossível) para um animal aprender alguma coisa, bem como se certas mudanças qualitativas podem ocorrer ou não em dada idade. Em uma próxima seção serão revisadas evidências que mostram a existência de períodos críticos e/ou de maior crescimento neurônico, o que suporta a hipótese bem conhecida de Piaget que o desenvolvimento cognitivo não é contínuo, mas procede através de diferentes estágios qualitativos. Antes, porém, parece interessante fazer uma breve revisão de como Piaget encarara a perspectiva neurobiológica, ainda que esse termo não fosse de uso comum na ocasião. 


\section{Piaget e a perspectiva neurobiológica}

À época de seus trabalhos tardios, Piaget reclamava que os psicólogos e epistemólogos se ocupam muito pouco da biologia e, por sua vez, os biólogos ignoravam os problemas da adaptação cognitiva (Piaget, 1970). Embora o quadro atual seja um pouco diferente, não está totalmente disseminado.

Em relação ao desenvolvimento cognitivo, ainda são necessárias muitas atividades de integração de campos de conhecimento. Nesse sentido, Piaget apontara que o problema essencial consistia em compreender o papel da atividade nervosa na passagem da assimilação material das substâncias e energias à assimilação funcional das informações exteriores, o que caracteriza a assimilação cognoscitiva (Piaget, 1967/1996, p. 250).

Conforme Bunge (1988) assevera, a investigação desse problema deve envolver as noções de biossistemas. E isso era muito caro a Piaget. Ele compreendera, a partir de seus resultados epistêmicos dos processos gerais de integração orgânica e mental, que as idéias de sistemas e de equilíbrio se impunham com toda a evidência (Piaget, 1977).

No nível neurológico, ele encontrara nos trabalhos de Weiss os conhecimentos sobre o substrato neurônico que corroboravam seus resultados epistêmicos. Piaget verificou que Weiss demonstrara, em 1969, que as variações de um sistema como unidade de conjunto são inferiores à soma das variações das partes. Então, se a totalidade varia menos que os seus elementos e esses são arrastados por um fluxo contínuo, é possível concluir que tal totalidade é o centro de uma dinâmica global, enquanto poder de integração e de direção. Dessa forma, supôs que parecia evidente que a coerência e a estabilidade do trabalho cognitivo fornecido pela atividade cerebral (e isso desde a memória elementar às ilações dedutivas mais sistemáticas) são o resultado não de conservações estáticas, mas de reconstrucões dinâmicas perpétuas (Piaget, 1977, p. 79).

$\mathrm{Na}$ tentativa de solucionar a questão sobre a reatividade nervosa, Piaget propõe a hipótese de que a reatividade nervosa (excitação e inibição) assegura a transição entre a assimilação fisiológica (ou seja, integração das substâncias e energias exteriores na estrutura e no funcionamento do organismo), e a assimilação cognoscitiva (i. e., a integração dos objetos ou situações nos esquemas de ação) e finalmente nos esquemas operatórios ou conceituais. Porém, faz questão se sublinhar que existem ainda atividades nervosas espontâneas e endógenas (Piaget, 1967/1996, p. 251).

Finalmente, serve de heurística registrar a preocupação que Piaget tinha em integrar conhecimentos científicos. Ele afirmara (Piaget, 1967/1996), p. ex., que a existência do desenvolvimento evolutivo ou genealógico se tornou cada vez mais provável devido aos resultados convergentes de quatro disciplinas distintas: a paleontologia, a anatomia comparada, a embriologia e a genética.
Essas diferentes disciplinas poderiam ser úteis para tematizar e atualizar os modelos teóricos de Piaget, principalmente o relacionado à equilibração das estruturas cognitivas. Isso pode servir como orientação para trabalhos futuros, por ora se quer empreender uma análise da perspectiva neurobiológica, que é mais recente e, talvez, mais influente.

\section{Perspectivas neurobiológicas}

O empreendimento científico de Jean-Piérre Changeux possui envergadura, não foi fortuito ele ter sido convidado para o simpósio de 1975. Na época ele despontava, estava com 39 anos e acabara de assumir como professor do College de France e como pesquisador no Institut Pasteur.

Além da intervenção de Changeux no simpósio, Piaget manifestou no seu ensaio sobre a evolução (Piaget, 1977) conhecer o trabalho de Changeux pela aula inaugural que ele dera ao assumir a cátedra no Collège de France. Nas citações que faz ao comentar a perspectiva psicobiológica, Piaget se apropria do que é declarado por Changeux para enfatizar a compreensão que a epigêenese funcional ... conduz a uma economia de genes (p. 146), bem como sua interpretação da aprendizagem, pelo qual o organismo torna-se receptivo a uma combinação de signos que também ele pode produzir (p. 147).

No entanto, provavelmente Piaget não chegou a conhecer o trabalho de Changeux em pormenores, não verificando as compreensões que eram dadas ao próprio mecanismo da epigênese funcional e sua relação com a interpretação da aprendizagem. Nesse sentido, é útil resgatar quais são as interpretações de Changeux para tal mecanismo. Isso pode, p. ex., ser feito através de seu livro de divulgação sobre a constituição neuronal do humano (Changeux, 1983/1997).

Nessa interpretação, diz-se que a máquina cerebral seria uma montagem de neurônios. Assim, os objetos mentais são identificados como um estado físico e material criado por atividade transiente, tanto elétrica quanto química, em uma reunião de neurônios em várias áreas corticais específicas. Essa reunião, que pode ser descrita matematicamente por gráficos neurais, seria discreta, fechada e autônoma, mas não homogênea. Por isso os neurônios apresentariam diferentes singularidades, construídas no curso do desenvolvimento embrionário e pós-natal. Quando cessa o desenvolvimento embrionário e o bebê humano nasce, os neurônios corticais parariam de se dividir. O seu número máximo seria então fixado, diminuindo em número através da vida.

Durante o desenvolvimento embrionário, até que a última divisão de neurônios tenha tomado lugar, axônio e as árvores dendríticas ramificariam e expandiriam exuberantemente. $\mathrm{O}$ crescimento seria excessivo e possibilitaria uma ampla diversidade de possíveis conexões sinápticas entre os neurônios. No entanto, esse estágio seria temporário e, posteriormente, um fenômeno regressivo rapidamente 
interferiria. Os neurônios morreriam e uma considerável porção de dendritos e de ramos de axônios seria podada. Assim, muitas atividades sinápticas desapareceriam. Os pulsos elétricos e químicos atravessariam a rede neurônica desde estágios muito iniciais de sua formação, colaborando para o mecanismo de seleção das conexões entre os neurônios. Os pulsos começariam espontaneamente, mas seriam depois evocados pela interação entre o recém-nascido e o seu ambiente.

Por isso, conforme Changeux (1983/1997), a feição principal das conexões entre os órgãos sensórios, o sistema nervoso central e os órgãos motores, bem como as conexões entre os principais centros do cérebro, estariam todos determinados ao nascimento. Cabendo a etapa de desenvolvimento pós-natal apenas a seleção das conexões previamente estabelecidas. A singularidade fenotípica estaria, assim, relacionada às possíveis diferente seleções que poderiam ser feitas na interação entre o sujeito em desenvolvimento e seu ambiente.

Por esse viés inatista, Changeux desenvolve uma proposição teórica para a epigênese chamada de estabilização seletiva das sinapses. Através dessa proposição, supõe-se que as principais características das organizações anatômica e funcional do sistema nervoso são preservadas de uma geração para outra e são sujeitas do determinismo do conjunto de genes que as produziram por um envelope genético. Esse envelope controla: 1) a divisão, a migração e diferenciação das células nervosas; 2) o comportamento do crescimento; 3) a identificação mútua por categorias de células; 4) a formação de conexões comuns; e, 5) o começo da atividade espontânea.

Changeux admite que existam poucos dados experimentais que corroborem esses postulados teóricos sobre a epigênese. No livro, apresenta dados relacionados à junção neuromuscular da galinha e do córtex cerebral de ratos. Por outro lado, ressalta que esses conceitos têm sido produzidos através de um modelo matemático, que seria, por necessidade, simplificado e esquemático, mas autônomo em relação à realidade biológica.

Resumindo a proposição teórica, se se considerar que o crescimento dos axônios e das árvores dendríticas é inato e que a estabilização seletiva define as características adquiridas, o inato pode ser diferenciado do adquirido somente por um detalhado estudo ao nível sináptico.

No entanto, esse estudo é dificultado pela íntima associação do crescimento e da epigênese e suas alteração no tempo. Assim, tem-se a impressão que o sistema começa mais ou menos ordenado e ele recebe instruções do meio ambiente. Se tal teoria está correta, a atividade espontânea ou evocada somente seria efetiva se neurônios e suas conexões existissem antes que a interação com o mundo externo acontecesse. A seleção epigenética influenciaria, portanto, o substrato sináptico. Dessa forma, conforme Changeux (1983/1997) aprender é estabilizar combinações sinápticas pré-estabelecidas, e eliminar o excesso. Por isso, aprender é eliminar (p. 229).

Conforme a interpretação da realidade biológica feita por Piaget $(1967 / 1996,1970,1977)$, haveria algum grau de relação entre as maturações biológica e a neurônica e o desenvolvimento cognitivo do indivíduo. Portanto, o mecanismo de organização neurônica postulado por Changeux muito pouco parece com os postulados epistemológicos enunciados por Piaget. Dessa forma, se a interpretação biológica e os postulados epistemológicos de Piaget estiverem corretos, é provável (no sentido que se pode provar) que a abstração da realidade, por privilégio ao modelo matemático, produza uma esperança que se mostre equivocada.

Porém, antes que se arrolem as evidências materiais que contrariam os postulados de Changeux e corroboram os de Piaget, é útil mostrar que há divergência e debate mesmo em relação aos modelos matemáticos.

\section{Os modelos matemáticos no estudo da atividade neuronal}

Em um artigo de revisão conceitual, Quartz (1993) mostra os equívocos conceituais em que recaem os inatistas, como Chomsky e Changeux. Esses equívocos estariam relacionados à interpretação que se dá para a aprendizagem em redes neurais. Assim, o que é necessário para refutar a posição inatista é compreender a característica não-estacionária dos sistemas em desenvolvimento.

O modelo construtivista, utilizado por Quartz (1993), é um exemplo bem conhecido na teoria da computação. Esse modelo agrega a propriedade pela qual o sistema pode fazer mudanças em seus mecanismos essenciais em resultado de mudanças da estrutura de dados que suportam o mecanismo. Dessa forma, as mudanças qualitativas se tornam de central importância e podem alterar as capacidades de aprendizagem dos sistemas que se desenvolvem.

Além do mais, são necessários modelos que incorporem a capacidade de um sistema poder ampliar seu potencial de representação - definida como o conjunto de conceitos que podem expressar - como uma função de aprendizagem. A arquitetura de uma rede é identificada com a classe de conceitos que ela pode representar. Isso sugere que uma rede com a habilidade de alterar sua arquitetura de formas apropriadas, como uma função da aprendizagem, será capaz de estender sua classe de representação além de seu estado inicial e por isso será capaz de adquirir novos conhecimentos.

A própria postulação teórica dos modelos computacionais que são utilizados para simular a correção das interpretações da realidade biológica do desenvolvimento neurônico é uma área de pesquisa. Os entendimentos de Quartz (1993) ganham algum refinamento através de Mareschal e Shultz (1997) e Molenaar e van der Maas (2000).

Psicologia: Reflexão e Crítica, 2005, 18(2), pp.255-266 
Os primeiros concordam que redes produtivas, isto é, redes que ampliam sua própria arquitetura como parte da aprendizagem, são melhor exploradas como modelo de desenvolvimento cognitivo. O algoritmo de correlação utilizado nesses modelos força a rede a se desenvolver inicialmente através de uma fase de limitado poder de representação e posteriormente através de sucessivas fases de ampliação do poder representacional. Dessa forma, as simulações sugerem que tal característica é necessária para apreender um desenvolvimento cognitivo realista.

Os segundos, por sua vez, sustentam que a explicação do processo de crescimento biológico, em particular do desenvolvimento no campo neural, parece requerer modelos dinâmicos não lineares ${ }^{6}$, esse é o caso de sistemas complexos, como os biossistemas. No entanto, eles discordam que a suposição do construtivismo neural (Quartz \& Sejnowski, 1997), dirigido por contínuas interações com um ambiente estruturado não estacionário ${ }^{7}$, seja suficiente para explicar o desenvolvimento cognitivo e, em particular, a ocorrência das transições de estágio, como empiricamente observados por diversos estudos. Então, para explicar os detalhes do crescimento neural e a emergência de estruturas mais poderosas, eles propõem um modelo em que a ocorrência de fases de transição de supercrescimento são um ingrediente necessário para a explicação do desenvolvimento neurônico.

Portanto, haveria plausibilidade matemática tanto para o modelo de selecionismo neural de Changeux, quanto para o construtivista de Quartz. Resta saber qual possui maior relação com a realidade. Existem diversas evidências que indicam a correção do modelo construtivista (Diamond, 2001; Epstein, 2001; Freeman, 1997; Quartz, 1999; Quartz \& Sejnowski, 1997; Rapoport, 1999).

\section{O debate atual sobre as perspectivas neurobiológicas.}

Visto de uma perspectiva desenvolvimental, a regra de Hebb foi uma proposta para como a modelagem da atividade neural poderia participar na construção de circuitos neurais. Nos anos recentes, acumula-se evidência para corroboração da proposta de Hebb para a atividade neural, tanto espontaneamente gerada quanto dependente da experiência, jogando um papel na construção dos circuitos corticais, mais que simplesmente selecionando entre os pré-existentes (Quartz, 1999).

O córtex cerebral, a área associada com o processamento cognitivo superior, é mais receptivo que outras partes do

\footnotetext{
${ }^{6}$ Isso é, modelos que não podem ser resolvidos matematicamente por equações lineares.

${ }^{7}$ Conforme a interpretação física, sistema não estacionário é o sistema em que ocorrem fenômenos de transporte de massa, de energia, etc., e em que existem modificações de suas variáveis macroscópicas.
}

cérebro ao crescimento neural relacionado ao enriquecimento ambiental. A partir disso, compreende-se que, embora o cérebro contenha uma organização macroestrutural constante, o córtex cerebral sempre muda em sua complexa microestrutura de potencial desconhecido. Essa microestrutura é formada por experiências antes do nascimento, durante a juventude e, de fato, através da vida. Vários estudos com ratos (Diamond, 2001), empreendidos por diversos padrões e mensurações químicas e anatômicas (espessura cortical, massa cortical, níveis de acetilcolinesterase, colinesterase, proteína e hexoquinase), permitiram verificar que a combinação de condições sociais e a exposição freqüente a novos objetos e estímulos foram necessárias para os animais ganharem o efeito completo do enriquecimento ambiental. É essencial notar que os efeitos do enriquecimento no cérebro têm conseqüência no comportamento Entretanto, é evidente que estabelecer o que constitui enriquecimento para os seres humanos é mais problemático.

Uma questão se faz necessária. Tais pesquisas foram feitas em laboratório, pode-se perguntar se em condições naturais, onde os próprios sujeitos podem procurar e escolher seu ambiente (social e físico e, no caso dos humanos, simbólico) esse enriquecimento não seria maior ainda. Isso seria uma forma, $\mathrm{p}$. ex., de saber como o comportamento, em sua autoregulação, influi. Piaget (1977), em seu estudo sobre a evolução, dá a entender que influi positivamente. Tal tese, sem dúvida, ainda necessita de corroboração.

Geralmente, reconhece-se que existem diferenças, pelo menos, qualitativas entre primatas em certos domínios cognitivos. Tais diferenças estariam particularmente relacionadas ao processo simbólico, a sintaxe, a linguagem e a autoconsciência. Além do mais, essas diferenças corresponderiam de algum modo a diferenças no tamanho e na organização do cérebro. Através de estudos com neuroimagens em primatas em situação de aprendizagem, Rapoport (1999) verificou que a ativação cerebral reduz a extensão da poda sináptica, mais uma vez corroborando a hipótese de Hebb. Assim, a adaptação dos primatas a novos ambientes cognitivos, sociais, culturais e comportamentais promoveria a elaboração dos circuitos cerebrais, auxiliando os processos cognitivos superiores.

Porém, o próprio mecanismo de crescimento neuronal pode ser, com certas restrições, interpretado pela perspectiva selecionista. Como foi visto, é central ao modelo selecionista a noção que há no início uma exuberante proliferação de sinapses ocorrendo, simultaneamente, através do córtex. Conhecida como sinaptogênese concorrente, essa influente visão foi baseada em estudos de microscopia eletrônica das sinaptogêneses no macaco rhesus.

No entanto, outros estudos (Quartz, 1999) com o desenvolvimento cortical humano no córtex auditivo e no giro pré-frontal sugerem que a sinaptogênese concorrente não é uma 
característica do desenvolvimento cortical humano. A sinaptogênese cortical humana ocorre regionalmente e de acordo com crescimento axonial e dendrítico e a mielinação da matéria branca subcortical. Através de diversas mensurações, verificouse que as áreas corticais sensório-primária e motor possuem proporções mais maduras ao nascimento, provavelmente por envolverem a ativação durante o período fetal. Por sua vez, o desenvolvimento pós-natal amplia sobremaneira as medidas iniciais das áreas associadas às regiões temporal e pariental e no córtex pré-frontal (CPF). Dessa forma, o desenvolvimento cortical pós-natal do humano é mais extensivo e retardado que geralmente suposto (Quartz \& Sejnowski, 1997).

Em relação às funções perceptivas, p. ex., estudos eletrofisiológicos da visão, audição, somático e olfativo tem mostrado que os padrões espaciais da atividade neural emergem pela construção de cada ato de percepção (Freeman, 1997). Esses padrões dependem do contexto presente e igualmente da experiência passada de cada sujeito, não meramente dos estímulos. Isso seria um reflexo da unidade da função do prosencéfalo.

Portanto, pode-se depreender que existe um debate sobre a base neural do desenvolvimento cognitivo. De um lado, haveria a posição inatista, representada pelo programa científico de Changeux. De outro lado, a posição que Quartz e Sejnowski (1997) defenderam em seu manifesto construtivista.

Estabelecida a controvérsia no debate, é necessário verificar uma resposta pelo ponto de vista de Changeux. No debate surgido após o manifesto construtivista (Quartz \& Sejnowski, 1997), a posição de Changeux foi defendida por alguns de seus colaboradores (Dehaene-Lamberzt \& Dehaene, 1997). Eles sustentam que, ao nível neurobiológico, todos os dados apresentados por Quartz e Sejnowski como suporte para o seu modelo construtivista são de fato compatíveis com o modelo composto de múltiplos estágios sobrepostos de superprodução sináptica e seleção. Em tal direção, revisam estudos desenvolvimentistas ao nível do comportamento humano, sustentando a evidência em favor do ponto de vista selecionista.

Entendem, ainda, que muitos dos argumentos contra a aprendizagem por seleção, apresentados por Quartz e Sejnowski, emergeriam de uma interpretação errônea das teorias selecionistas do desenvolvimento cognitivo e neural. Assim, Quartz e Sejnowski teriam produzido uma versão simplificada que dividiria, de forma equivocada, o desenvolvimento em dois estágios: primeiro, a produção intrínseca de pré-representação, e segundo, sua eliminação seletiva ou estabilização. Então, eles passaram à forçada conclusão que para o selecionismo, o desenvolvimento seria marcado por uma redução na complexidade representacional. Essa caracterização supersimplificada é, por fim, mostrada como sendo incompativel com numerosos dados que ressaltam o enriquecimento progressivo em número de sinapses, de árvores dendríticas e de arborização axonial que acompanham o desenvolvimento cognitivo.

Os Dehaene entendem que o uso do vocabulário mentalístico de Quartz e Sejnowski, que trata simples dendritos como agentes cognitivos, feitos por uma analogia enganadora e mal especificada, é substituído, nas teorias selecionistas, por um simples, explícito e empiricamente testável mecanismo de estabilização que foi desenvolvido por Changeux. O qual Quartz e Sejnowski não teriam compreendido ou levado em conta.

Porém, mais uma vez surgem argumentos retóricos. Os Dehaene, a seguir, passam a desmerecer as contribuições de Piaget. Entendem, também por uma rudimentar simplificação, que ao nivel cognitivo, a noção piagetiana que as representacões mentais são construídas através da instrução progressiva dos inputs ambientais é agora obsoleto (p. 561). Obviamente, Piaget não disse isso. Então, apresentam dados que contrariariam tal idéia, enfatizando as competências iniciais das crianças, principalmente, em relação aos domínios do processamento numérico e da aquisição da linguagem.

$\mathrm{Na}$ aquisição da linguagem, p. ex., durante o primeiro ano de vida, os Dehaene se municiam de um amplo conjunto de dados que deporiam contra a aprendizagem construtivista e suportariam o ponto de vista selecionista do desenvolvimento. Citam pesquisas, p. ex., que mostram que desde o nascimento os bebês humanos discriminam contrastes fonéticos, incluindo aqueles que não são usados em sua linguagem materna. Por sua vez, isso está longe de depor contra o entendimento piagetiano, como demonstram Perruchet e Vinter (1998).

$\mathrm{Na}$ avaliação das críticas feitas, pelos Dehaene e por outros autores, ao seu manifesto construtivista, Quartz e Sejnowski concluem que o valor real das teorias globais a esse estágio da neurociência cognitiva não é tanto por suas respostas, mas mais pelo novo conjunto de questões de pesquisa que são propostas. Portanto, o que as ciências cognitivas devem pegar da neurobiologia não é tanto se o meio ambiente influencia o desenvolvimento cerebral, mas como isso acontece.

Em relação à réplica dos Dehaene, Quartz e Sejnowski sustentam que nenhum dos argumentos que apresentaram contra o selecionismo depende da interpretação de seu mecanismo. Então, procuram recolocar o problema sobre a seguinte questão:

se o desenvolvimento é uma expansão progressiva da estrutura neural, é o processo de expansão por ele mesmo insensível ao padrão ambientalmente derivado da atividade neural, ou essa atividade joga um papel central e específico na construção de circuitos neurais? (p. 584)

As razões biológicas por que a atividade pode jogar um papel específico no crescimento neural regulado parece bastante claro para Quartz e Sejnowski. A demanda metabólica humana é custosa, e em criaturas com cérebro largo, como o nosso, 
colocam-se pressões severas na aquisição de comida suficiente. De acordo com a interpretação selecionista, o cérebro adulto poderia ser construído com uma quantidade massiva de estrutura em excesso, que em toda a mudança poderia ser estabilizado. Embora isso seja uma possibilidade, parece que a mais razoável suposição é que a atividade inicie e guie a construção de circuitos específicos. O ponto crucial da posição de Quartz e Sejnowski é que a atividade ambientalmente derivada ajuda a guiar o progressivo crescimento neural pela regulação da excrescência dendrítica e axonial, ao nível dos segmentos individuais.

Finalmente, e bem ao estilo piagetiano, Innocenti (1997) apresenta uma proposta integradora, que propõe um compromisso entre o selecionismo e o construtivismo neural, através de uma abordagem que ele chama de diferenciacionismo neural. Para sustentar seu ponto de vista, exemplificando-o, traz dados sobre o desenvolvimento dos axônios caloso-visual, provavelmente o único axônio cortical amplamente estudado quantitativamente desde as fazes de elongação (das estruturas anatômicas) até a eliminação sináptica e por entre a idade adulta. Esses axônios são fenótipos adultos bem definidos, bem apropriados para implementar muitas operações computacionais. Esses fenótipos são adquiridos em estágios.

Os estágios (elongação, ramificação subcortical, crescimento e ramificação da matéria cinza, sinaptogênese, eliminação sináptica) são provavelmente a expressão de programas celulares autônomos, mas eles necessitam ser desencadeados por sinais externos. A cada estágio, ocorre um crescimento exuberante, seguido por regressão, ambas etapas provavelmente controladas por sinais externos. O processo global é uma diferenciação condicional celular, resultando em uma diferenciação dos circuitos neurais. Dessa forma, Innocenti entende que esse princípio tem a vantagem de ser aplicado a todos os desenvolvimentos celulares e de sistemas, não somente ao sistema nervoso. Assim como tem a desvantagem de não ser particularmente novo, embora tenha sido algumas vezes negligenciado por neurobiólogos desenvolvimentistas.

Curiosamente, esse mecanismo pode ser tomado em termos piagetianos. Pode-se interpretar a diferenciação condicional como um processo de equilibração, em que a fase de crescimento exuberante poderia ser interpretada como a assimilação, enquanto, a fase de regressão seria a acomodação. Quanto à existência de estágios no desenvolvimento neural, ainda que se guardem as diferentes particularidades, Epstein (2001) mostrou que existe uma correlação entre os estágios de desenvolvimento cognitivo propostos por Piaget e os estágios de desenvolvimento da rede neural. Nesse ocorre uma passagem qualitativamente marcada por fases de supercrescimento da estrutura neural, que envolvem a integração de redes neurais diferenciadas em fases anteriores de crescimento estável.

\section{Conclusões}

Neste artigo, procurou-se mostrar que o debate em torno de teses científicas pode ser eclipsado se os argumentos retóricos, que são empregados de parte a parte na enunciação dos diferentes pontos de vista, não forem abstraídos. Dessa forma, tentou-se mostrar como mesmo um participante privilegiado de um debate entre os programas científicos de Chomsky e de Piaget acaba por organizar os depoimentos desse debate, e revisá-lo quase vinte anos depois, desenvolvendo argumentos de cunho retórico, em favor da tese inatista, ou nativista, de Chomsky, em detrimento da tese construtivista de Piaget.

Assim, seguindo a orientação filosófica do materialismo emergentista, buscou-se mostrar como esse debate pode ser reorientado por perspectivas neurobiológicas. Essa reorientação, finalmente, mostrou que o debate ainda continua aberto e que parece precipitado querer sustar o crédito de quaisquer das proposições arroladas.

Ainda que o debate entre as posições de Chomsky e Piaget seja muito mais amplo, neste artigo se procurou atualizar e tematizar o debate apenas entre as posições sobre o inato e o adquirido. Uma ampliação do debate aqui descrito, em relação à natureza da linguagem e sua aquisição, pode ser encontrado em perspectivas neurobiológicas na análise de Müller (1996).

Finalmente, no seu verbete sobre a retórica, Abbagnano (1999) conclui que:

se a razão é infalível e a investigação humana pode ser confiada às suas regras infalíveis em qualquer campo, não há lugar para a retórica, que é a arte da persuasão. Mas, se, na esfera do saber humano, a parte do incerto, do provável, do aproximativo é mais ou menos ampla, a persuasão pode ter alguma função e sua arte pode ser cultivada. (p. 857)

Porém, o cultivo dessa arte tem apresentado uma realização perigosa. Nesse sentido, p. ex., Quartz e Sejnowski (2000), ao concordar com as posições de Molenaar e van der Maas (2000) e de Mareschal e Shultz (1997), concluem que o estudo do desenvolvimento cognitivo tem sido oprimido por um debate que tem causado mais polarização do que pesquisa produtiva.

\section{Referências}

Abbagnano, N. (1999). Dicionário de filosofia. São Paulo: Martins Fontes. Bunge, M. \& Ardila, R. (1987). Philosophy of psychology. New York: Springer-Verlag. Bunge, M. (1988). Elproblema mente-cerebro: Un enfoque psicobiologico. Madrid: Tecnos. Changeux, J. -P. (1987). Determinismo genético e epigênese das redes de neurônios: Existe um compromisso biológico possível entre Chomsky e Piaget? Em M. Piattelli-Palmarini (Org), Teorias da linguagem, teorias da aprendizagem: Debate de Jean Piagete Noam Chomsky com outros autores (pp. 267-280). Lisboa: Edições 70. (Original publicado em 1978)

Changeux, J.-P. (1997). Neuronal man: The biology of mind. Princeton: University Press. (Original publicado em 1983) 
Chomsky, N. (1987). A propósito das estruturas cognitivas e do seu desenvolvimento: Uma resposta a Piaget. Em M. Piattelli-Palmarini (Org), Teorias da linguagem, teorias da aprendizagem: debate de Jean Piaget e Noam Chomsky com outros autores (pp. 63-84). Lisboa: Edições 70. (Original publicado em 1978)

Dehaene-Lambertz, G. \& Dehaene, S. (1997). In defense of learning by selection: Neurobiological and behavioral evidence revisited. Behavioral and Brain Sciences, 20, 560-561.

Diamond, M. C. (2001). Response of brain to enrichment. Anais da Academia Brasileira de Ciências, 73 (Versão digital em http://www.scielo.br)

Epstein, H. T. (2001). An outline of the role of brain in human cognitive development. Brain and Cognition, 45, 44-51.

Freeman, W. J. (1997). Three centuries of category errors in studies of the neural basis of conciousness and intentionality. Neural Networks, 10, 1175-1183.

Gould, S. J. (1992). Darwin e os enigmas da vida. São Paulo: Martins Fontes.

Hegenberg, L. (1969). Explicações científicas: Introdução à filosofia da ciência. São Paulo: Herder.

Inhelder, B. (1987). Linguagem e conhecimento no quadro do construtivismo. Em M. Piattelli-Palmarini (Org.), Teorias da linguagem, teorias da aprendizagem: Debate de Jean Piaget e Noam Chomsky com outros autores (pp.195-202). Lisboa: Edições 70. (Original publicado em 1978)

Innocenti, G. M. (1997). "Differentiationism" can reconcile selectionism and construtivism. Behavioral and Brain Sciences, 20, 568-569.

Leakey, R. E. (1994). A origem da espécie humana. Rio de Janeiro: Rocco.

Mareschal, D. \& Shultz, T. R. (1997). From neural construtivism to children's cognitive development: Bridging the gap. Behavioral and Brain Sciences, 20, 565566.

Molenaar, P.C. \& van der Maas, H. L. J. (2000). Neural constructivism or selforganization? Behavioral and Brain Sciences, 23, 783-784.

Müller, R. -A. (1996). Innateness, autonomy, universality? Neurobiological approaches to language. Behavioral and Brain Sciences, 19, 611-675.

Papert, S. (1987). O papel da inteligência artificial em psicologia. Em M. PiattelliPalmarini (Org.), Teorias da linguagem, teorias da aprendizagem: Debate de Jean Piaget e Noam Chomsky com outros autores (pp.143-152). Lisboa: Edições 70. (Original publicado em 1978)

Perruchet, P. \& Vinter, A. (1998). PARSER: A model for word segmentation. Journal of Memory and Language, 39, 246-263.
Piaget, J. (1970). Inteligencia e adaptación biológica. Em J. Nuttin \& J. Piaget (Orgs.), Los procesos de adaptación (pp. 69-84). Buenos Aires: Proteo.

Piaget, J. (1977). Comportamento motriz da evolução. Porto: Res.

Piaget, J. (1987). A psicogênese dos conhecimentos e a sua significação epistemológica. Em M. Piattelli-Palmarini (Org.), Teorias da linguagem, teorias da aprendizagem: debate de Jean Piaget e Noam Chomsky com outros autores (pp. 51-62). Lisboa: Edições 70. (Original publicado em 1978)

Piaget, J. (1996). Biologia e conhecimento: Ensaio sobre as relações entre as regulações orgânicas e os processos cognitivos. Petrópolis, RJ: Vozes. (Original publicado em 1967)

Piattelli-Palmarini, M. (1987). Teorias da linguagem, teorias da aprendizagem: Debate de Jean Piaget e Noam Chomsky com outros autores. Lisboa: Edições 70. (Original publicado em 1978)

Piattelli-Palmarini, M. (1994). Ever since languague and learning: Afterthoughts on the Piaget-Chomsky debate. Cognition, 50, 315-346.

Quartz, S. R. \& Sejnowski, T. J. (1997). The neural basis of cognitive development: A constructivist manifesto. Behavioral and brain sciences, 20, 537-596.

Quartz, S. R. \& Sejnowski, T. J. (2000). Constraining constructivism: Cortical and sub-cortical constrains on learning in development. Behavioral and brain sciences, 23, 785-792.

Quartz, S. R. (1993). Neural networks, nativism, and the plausibility of constructivism. Cognition, 48, 223-242.

Quartz, S. R. (1999). The constructive brain. Trends in Cognitive Sciences, 3, 48-57.

Rapoport, S. I. (1999). How did the human brain evolve? A proposal based on new evidence from in vivo brain imaging during attention and ideation. Brain Research Bulletin, 50, 149-165.

Regner, A. C. K. P. (1998). Argumentos retóricos na ciência: re-pensando Aristóteles. Episteme (Porto Alegre), 3, 64-83.

Rieber, R. W. \& Voyat, G. (1981). An overview of the controversial issues in the psychology of language and thought. Journal of Psycholinguistic Research, 10, 341-361.

Toulmin, S. (1987). Para uma via entre construtivismo e inatismo. Em M. PiattelliPalmarini (Org.), Teorias da linguagem, teorias da aprendizagem: debate de Jean Piaget e Noam Chomsky com outros autores (pp. 389-391). Lisboa: Edições 70. (Original publicado em 1978)

Sobre os autores:

Marcelo Leandro Eichler é Químico, Mestre e Doutor em Psicologia do Desenvolvimento pela Universidade Federal do Rio Grande do Sul. É Professor da Universidade Estadual do Rio Grande do Sul.

Lea Fagundes é Professora na Universidade Federal do Rio Grande do Sul. 